\title{
Semi-Analytical Resolution of a Squeezing Unsteady Nanofluid Flow Between Two Parallel Plates Using Homotopy Perturbation Method (HPM)
}

\author{
A. EL HARFOUF ${ }^{1}$, A. WAKIF ${ }^{2 *}$, S. HAYANI MOUNIR ${ }^{1}$ \\ ${ }^{1}$ Sultan Moulay Slimane University of Beni Mellal, Polydisciplinary Faculty of Khouribga, Research Team \\ of Energy, Materials, Atomics and Information Fusion, BP: 145 Main Khouribga, 25000, Morocco \\ ${ }^{2}$ Hassan II University, Faculty of Sciences Aïn Chock, Laboratory of Mechanics, B.P.5366 Mâarif, \\ Casablanca, MOROCCO.
}

\begin{abstract}
In this current work, the heat transfer analysis for the unsteady squeezing flow of a viscous nanofluid between two parallel plates considering Fourier heat flux model have been explored. The partial differential equations representing flow model are reduced to nonlinear ordinary differential equations by introducing a similarity transformation. The dimensionless and nonlinear ordinary differential equations of the velocity and temperatures functions obtained are solved by employing The Homotopy Perturbation Method (HPM). The results found in this peper are verified by comparing it with the results obtained using the numerical method RK4, The results obtained are agree with this numerical solution. The effects of different parameters on the velocity and temperature profiles are examined graphically, and numerical calculations for the skin friction coefficient and local Nusselt number are tabulated. It is found an excellent agreement in the comparative study with literature results.
\end{abstract}

Keywords : Heat transfer, Squeezing flow, nanofluid, Homotopy Perturbation method, RK4.

Received: August 6, 2020. Revised: December 24, 2020. Accepted: January 9, 2021. Published: January 19, 2021.

\section{Introduction}

Nanofluids are widely encountered in many industrial and technology applications, for example, melts of polymers, biological solutions, paints, asphalts and glues, etc. Nanofluids appear to have the potential to significantly increase heat transfer rates in a variety of areas, The word nanofluid represents the fluid in which particles of size with order of nanometer (diameter $<$ $100 \mathrm{~nm}$ ) are mixed in the base fluid. The nanoparticles used in nanofluids are generally made of metals (Al, $\mathrm{Cu}$ ), oxides ( $\mathrm{Al} 2 \mathrm{O} 3, \mathrm{CuO}, \mathrm{TiO} 2$, and $\mathrm{SiO} 2)$, carbides (SiC), nitrides (AlN, SiN), and nonmetal (graphite, carbon nanotubes) and the base fluid is usually a conductive fluid, such as water or ethylene glycol. Other base fluids are toluene, oil, other lubricants, biofluids, and polymer solution. Nanoparticles are present up to $5 \%$ volume fraction in nanofluids. The conventional heat transfer fluids are poor conductors of heat. Nanofluids make an edge over them because they have high heat transfer capability. Since these heating/cooling fluids play a vital role in the development of energy efficient heat transfer equipment for energy supply, to raise the thermal conductivity of these fluids, nanosized conducting metal particles are added to them. Therefore, their proper understanding is a must to use them efficiently in modern industry. Applications of nanofluids include microelectronics, fuel cells, and pharmaceutical processes, Choi and Eastman [1] were the first to propose the term nanofluid that represents the fluid in which nanoscale particles are suspended in the base fluid with low thermal conductivity such as water, 
ethylene glycol, and oil. In recent years, many researchers have studied and reported nanofluid technology experimentally or numerically in the presence of heat transfer.

The study of heat and mass transfer in unsteady squeezing viscous nanofluid flow between two parallel plates is a stimulating topic of exploration because of its industrial use and intense biological situations, some of which include processing of polymer, compression, power transmitting, lubricant system, transient loading of mechanical components and the squeezed films in power transmission, food processing, and cooling water, modeling of synthetics transportation inside living bodies, hydromechanical machinery, chemical processing equipment, and crop destruction due to freezing. The first work on the squeezing flow under lubrication approximation was studied by Stefan [2].The flow analysis between two parallel plates of $\mathrm{Cu}$-water squeezing nanofluid was investigated by Domairry and Hatami [3]. The squeezing flow of $\mathrm{Cu}$-water (or kerosene) nanofluid between two parallel plates under the effects of viscous dissipation and velocity slipwas investigated by Khan et al. [4]. Heat transfer of a nanofluid flow which is squeezed between parallel plates was investigated analytically using Homotopy perturbation method (HPM) by Sheikholeslami and Ganji [5].They reported that Nusselt number has direct relationship with nanoparticle volume fraction, the squeeze number and Eckert number when two plates are separated but it has reverse relationship with the squeeze number when two plates are squeezed.

Most of engineering problems, especially some heat transfer equations are nonlinear, therefore some of them are solved using numerical solution and some are solved using the different analytic method, such as perturbation method (PM), homotopy perturbation method (HPM), variational iteration method (VIM). Therefore, many different methods have recently introduced some ways to eliminate the small parameter. One of the semiexact methods which does not need small parameters is the HPM. The homotopy perturbation method proposed and improved by $\mathrm{He}$ [6]. The method yields a very rapid convergence of the solution series in the most cases. The HPM proved its capability to solve a large class of nonlinear problems efficiently, accurately and easily with approximations convergency very rapidly to solution. Usually, few iterations lead to high accuracy solution. This method is employed for many researches in engineering sciences. HPM was used for solving meany problems such as : nonlinear MHD Jeffery Hamel problem by Moghimi et al. [7]. Mustafa et al. [8] analyzed the effect of squeezing nanofluid flow between parallel plates, Siddiqui et al. [9] used this method for solving non-linear problems involving Newtonian and non-Newtonian fluids, For a comprehensive account of the use of the HPM successfully to solve problems in fluid mechanics, please see $[10,11,12]$.

The main objective of this present work is to investigate nanofluid flow and heat transfer between two parallel flat plates without presence of constant magnetic field. In this study, we have applied The Homotopy Perturbation method (HPM), to find the solution of nonlinear differential equations of velocity and temperature, The impacts of diverse active parameters such as : 
the squeeze number $(S)$, the volume fraction of nanofluid $(\varphi)$, the Eckert number $(E c)$, the of Prandtl number $(\mathrm{Pr})$ on flow and heat transfer characteristics are examined.

\section{Mathematical Formulation}

In this present study, analysis of flow and heat transfer in the unsteady squeezing two dimensional incompressible newtonian nanofluid flow allong two infinite parallel plates have been investigated. The flow configuration is modeled in such way that, the plates are separated by a distance $y= \pm h(t)= \pm \mathrm{l} \sqrt{1-\alpha t}$, where $l$ is the initial location between the two plates (when time $t=0)$. However, the parallel plates are squeezed when $\alpha>0$ till they reach $t=1 / \alpha$ and plates are separated when $\alpha<0$. Cartesian coordinate system is considered to describe this problem, in which, $\mathrm{x}$-axis is considered along the axial flow direction and y-axis is taken normal to the axial direction. Figure 1 clearly describes the geometry and coordinate system of the considered problem. The continuity, momentum, vorticity and energy equations governing such type of flow are given as

$$
\frac{\partial u}{\partial x}+\frac{\partial v}{\partial y}=0
$$

$$
\begin{array}{r}
\rho_{n f}\left(\frac{\partial u}{\partial t}+u \frac{\partial u}{\partial x}+v \frac{\partial u}{\partial y}\right)=-\frac{\partial P}{\partial x}+\mu_{n f}\left(\frac{\partial^{2} u}{\partial x^{2}}+\frac{\partial^{2} u}{\partial y^{2}}\right) \\
\rho_{n f}\left(\frac{\partial v}{\partial t}+u \frac{\partial v}{\partial x}+v \frac{\partial v}{\partial y}\right)=-\frac{\partial P}{\partial y}+\mu_{n f}\left(\frac{\partial^{2} v}{\partial x^{2}}+\frac{\partial^{2} v}{\partial y^{2}}\right) \\
\frac{\partial T}{\partial t}+u \frac{\partial T}{\partial x}+v \frac{\partial T}{\partial y} \\
=\frac{k_{n f}}{\left(\rho c_{p}\right)_{n f}}\left(\frac{\partial^{2} T}{\partial x^{2}}+\frac{\partial^{2} T}{\partial y^{2}}\right) \\
+\frac{\mu_{n f}}{\left(\rho c_{p}\right)_{n f}}\left[4\left(\frac{\partial u}{\partial x}\right)^{2}+\left(\frac{\partial u}{\partial y}+\frac{\partial v}{\partial x}\right)^{2}\right] \\
u \frac{\partial \square}{\partial x}+v \frac{\partial \square}{\partial y}=\frac{\mu_{n f}}{\rho_{n f}}\left(\frac{\partial^{2} \square}{\partial x^{2}}+\frac{\partial^{2} \square}{\partial y^{2}}\right)
\end{array}
$$

equation (5) is called the vorticity equation is obtained by doing : $\frac{\partial(3)}{\partial x}-\frac{\partial(2)}{\partial y}$ with $\square=\frac{\partial v}{\partial x}-$ $\frac{\partial u}{\partial y}$

where $u$ and $v$ are the velocity components in the $\mathrm{x}$ and $\mathrm{y}$ directions, respectively, $\rho_{n f}$ is the effective density of the nanofluid, $\mu_{n f}$ is the effective dynamic viscosity of the nanofluid, $\left(\rho c_{p}\right)_{n f}$ is the heat capacity of the nanofluid and $k_{n f}$ is the thermal conductivity of the nanofluid, are given

as :

\section{Unsteady Squeezing Flow}

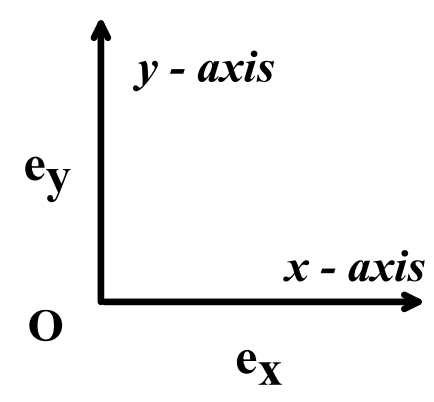

$$
u=0, v=\frac{d h}{d t}
$$

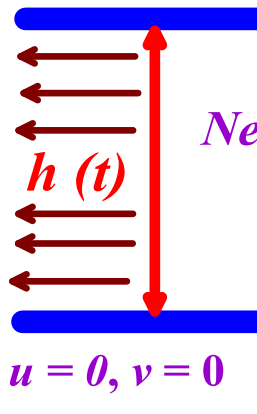

$v=\frac{d h}{d t}$

$$
T=T_{2}
$$

$\{$ Upper plate $(y=h(t))\}$ Newtonian Nanofluide Flow

(Copper + Water)

$\{$ Lower plate $(y=0)\}$

$$
h(t)=\sqrt{1-\alpha t}
$$


Figure 1: Geometry of present work.

$$
\begin{gathered}
\rho_{n f}=(1-\phi) \rho_{f}+\phi \rho_{p} \\
(\rho C p)_{n f}=(1-\phi)(\rho C p)_{f}+\phi(\rho C p)_{p} \\
\mu_{n f}=\frac{\mu_{f}}{(1-\phi)^{2.5}} \\
K_{n f}=\frac{K_{s}+2 K_{f}-2 \phi\left(K_{f}-K_{s}\right)}{K_{s}+2 K_{f}+2 \phi\left(K_{f}-K_{s}\right)} K_{f}
\end{gathered}
$$

The associated boundary conditions for the time dependent squeezing flow are as follows :

$$
\begin{gathered}
u=0, v=0, T=T_{1} \quad \text { en } \quad y=0 \\
u=0, v=\frac{d h}{d t}, T=T_{2} \quad \text { en } \quad y=h(t)
\end{gathered}
$$

In the Eq. (11), $v=\frac{d h}{d t}$ indicate the velocity with which upper plate is moving towards or away from the lower plate which is kept at a distance $y=0$ from the upper plate at $y=h(t)$. Further, the value of the $v$ is exam as $\left[\frac{-\alpha l}{2(1-\alpha t)^{\frac{1}{2}}}\right]$. However, Eqs. (4)-(5) along with conditions (10) and (11) governing the nanofluid squeezing flow are coupled highly nonlinear in nature and are not amenable to any analytical methods. Hence, in the system of partial differential equations, Eqs. (4)(5) are reduced to ordinary differential equations by using the following similarity transf ormations :

$$
\begin{gathered}
\eta=\frac{y}{l(1-\alpha t)^{\frac{1}{2}}}=\frac{y}{h(t)} \\
u=\frac{\alpha x}{2(1-\alpha t)} f^{\prime}(\eta) \\
v=\frac{-\alpha l}{2(1-\alpha t)^{\frac{1}{2}}} f(\eta) \\
\Theta=\frac{T-T_{2}}{T_{1}-T_{2}}
\end{gathered}
$$

and substituting Eq. (12) in Eqs. (5) and (6), we obtain the reduced governing equations :

- The nonlinear fourth-order ordinary differential equation for the momentum equation :

$$
f^{\prime \prime \prime \prime}-S \frac{A_{1}}{A_{2}}\left(3 f^{\prime \prime}+\mathrm{n} f^{\prime \prime \prime}+f^{\prime} f^{\prime \prime}-f f^{\prime \prime \prime}\right)=0
$$

- The second order differential equation for

$$
\begin{aligned}
\Theta^{\prime \prime}+\operatorname{SPr} \frac{A_{4}}{A_{3}}\left(f \Theta^{\prime}-\mathrm{\eta} \Theta^{\prime}\right) \\
+\left(P_{r} E_{c} \frac{A_{2}}{A_{4}}\right)\left(f^{\prime \prime 2}+4 \delta^{2} f^{\prime 2}\right)=0
\end{aligned}
$$

the energy equation :

where $A_{1}, A_{2}$ and $A_{3}$ are dimensionless constants defined as follows :

$$
\begin{gathered}
A_{1}=\frac{\rho_{n f}}{\rho_{f}} \\
A_{2}=\frac{\mu_{n f}}{\mu_{f}} \\
A_{3}=\frac{K_{n f}}{K_{f}} \\
A_{4}=\frac{\left(\rho c_{p}\right)_{n f}}{\left(\rho c_{p}\right)_{f}}
\end{gathered}
$$

The boundary conditions (10) in the terms of similarity variables (11) become :

$$
\begin{aligned}
& f^{\prime}(0)=0, f(0)=0, \Theta=1 \quad \text { at } \quad \eta=0 \\
& f^{\prime}(1)=0, f(1)=1, \Theta=0 \quad \text { at } \quad \eta=1
\end{aligned}
$$


where $S=\frac{\alpha l^{2}}{2 v_{f}}$ is the squeeze number, $\operatorname{Pr}=$ $\frac{(\rho C p)_{f}}{K_{f}} \mathrm{v}_{f}$ is the Prandtl number and $E_{c}=$ $\frac{\alpha^{2} x^{2}}{\left(T_{1}-T_{2}\right) c_{p_{f}}}$

The physical quantities of interest are the skinfriction coefficient $C_{f}$, the Nusselt number $N_{u}$, defined as :

$$
\begin{gathered}
c_{f}=\frac{\tau_{w}}{\rho_{n f} \mathrm{v}_{w}} \\
N_{u}=\frac{l q_{w}}{k_{f}\left(T_{1}-T_{2}\right)}
\end{gathered}
$$

Where :

$$
\begin{aligned}
& \tau_{w}=\mu_{n f}\left(\frac{\partial u}{\partial y}\right)_{y=0} \\
& \left.q_{w}=-k_{n f} \frac{\partial T}{\partial y}\right)_{y=0}
\end{aligned}
$$

Using (7) and (11) in (10),we get :

$$
\begin{gathered}
C_{f}^{*}=\frac{x^{2}}{l^{2}}(1-\alpha t) R_{e_{x}} C_{f}=\frac{f^{\prime \prime}(0)}{(1-\phi)^{2.5} A_{1}} \\
N_{u_{x}}^{*}=\sqrt{1-\alpha t} N_{u_{x}}=-A_{3} \Theta^{\prime}(0)
\end{gathered}
$$

Where $R_{e_{x}}=\frac{\alpha l^{5}}{2 x^{3}(1-\alpha t)^{\frac{1}{2} v_{f}}}$ the local Reynolds number.

\section{Basic Idea of the Homotopy Perturbation Method}

To illustrate the basic ideas of this method, we consider the following equation :

$$
A(u)-f(r)=0, \quad r \in \Omega
$$

with the boundary condition of :

$$
B\left(u, \frac{\partial U}{\partial n}\right)=0, \quad r \in \Gamma
$$

where $A$ is a general differential operator, $B$ a boundary operator, $f(r)$ a known analytical function and $\Gamma$ is the boundary of the domain $\Omega$. $A$ can be divided into two parts which are $L$ and $N$, where $L$ is linear and $N$ is nonlinear. Eq. (16) can therefore be rewritten as follows :

$$
L(u)+N(u)-f(r)=0
$$

Homotopy perturbation structure is shown as follows :

$$
\begin{gathered}
H(v, p)=(1-p)\left[L(v)-L\left(u_{0}\right)\right]+p[L(v)+N(v) \\
-f(r)]=0
\end{gathered}
$$

Where :

$$
v(r, p): \Omega \times[0,1] \rightarrow R
$$

In Eq. (22), $p \in[0,1]$ is an embedding parameter and $0 \mathrm{u}$ is the first approximation that satisfies the boundary condition. We can assume that the solution of Eq. (21) can be written as a power series in $\mathrm{p}$, as following :

$$
v=v_{0}+p v_{1}+p^{2} v_{2}+p^{3} v_{3}+\cdots
$$

and the best approximation for solution is :

$$
u=\lim _{p \rightarrow 1} v=v 0+v 1+v 2+\cdots
$$

\section{Implementation of the method}

According to the so-called homotopy-perturbation method (HPM), we construct a homotopy suppose the solution of Eq. (17) has the form :

$$
(1-p)\left[f^{\prime \prime \prime \prime}-f_{0}{ }^{\prime \prime \prime \prime}(0)\right]
$$

$$
\begin{aligned}
& +p\left[f^{\prime \prime \prime \prime}+S A_{1}(1\right. \\
& -\phi)^{2.5}\left[3 f^{\prime \prime}+\mathrm{n} f^{\prime \prime \prime}+f^{\prime} f^{\prime \prime}\right. \\
& \left.\left.-f f^{\prime \prime \prime}\right]\right]=0
\end{aligned}
$$

$$
\begin{aligned}
& (1-p)\left[\Theta^{\prime \prime}-\Theta_{0}{ }^{\prime \prime}(0)\right] \\
& \quad+p\left\{\Theta^{\prime \prime}+S \operatorname{Pr} \frac{A_{2}}{A_{3}}\left[f \Theta^{\prime}-\eta \Theta^{\prime}\right]\right\}=0
\end{aligned}
$$

We consider $f$ and $\theta$ as follows : 


$$
\begin{array}{r}
f(\eta)=f_{0}(\eta)+f_{1}(\eta)+f_{2}(\eta)+f_{3}(\eta)+\cdots \\
=\sum_{i=0}^{N} f_{i}(\eta) \\
\theta(\eta)=\theta_{0}(\eta)+\theta_{1}(\eta)+\theta_{2}(\eta)+\theta_{3}(\eta)+\cdots \\
=\sum_{i=0}^{N} \theta_{i}(\eta)
\end{array}
$$

with substituting $f, \theta$ from equations (20 - 21) into equations (18-19) and some simplification and rearranging based on powers of $p$ - terms, we have :

$$
\begin{gathered}
p^{0}: \\
f^{i v}=0, \\
\theta_{0}^{\prime \prime}=0,
\end{gathered}
$$

And boundary conditions are :

$f(0)=0, f^{\prime}(0)=0, f(1)=1, f^{\prime}(1)=0, \theta(0)=1$ et

$$
\theta(1)=0
$$

$$
\begin{gathered}
P^{I}: \\
f_{1}^{i v}-1.102087119 S\left(\eta f_{0}^{\prime \prime \prime}+3 f_{0}^{\prime \prime}+f_{0}^{\prime} f_{0}^{\prime \prime}-f_{0} f_{0}^{\prime \prime \prime}\right) \\
=0 \\
\Theta_{1}^{\prime \prime}+0.9201899729 \operatorname{Pr} S\left(\Theta_{0}^{\prime} f_{0}-\eta \Theta_{0}^{\prime}\right)=0
\end{gathered}
$$

And boundary conditions are :

$f(0)=0, f^{\prime}(0)=0, f(1)=0, f^{\prime}(1)=0, \quad \theta(0)=0$ et $\theta(1)=0$

Solving equations (22) and (24) with boundary conditions, we have :

$$
\begin{gathered}
f_{0}=-2 \eta^{3}+3 \eta^{2} \Theta_{0}=-\eta+1 \\
f_{1}=\frac{3306261357}{500000000} S\left(\frac{1}{105} \eta^{7}-\frac{1}{30} \eta^{6}-\frac{1}{60} \eta^{5}+\frac{1}{8} \eta^{4}\right) \\
-\frac{472323051}{625000000} \eta^{3} S+\frac{157441017}{800000000} \eta^{2} S
\end{gathered}
$$

$$
\begin{gathered}
\theta_{1}=-\frac{9201899729}{10000000000} \operatorname{SPr}\left(\frac{1}{10} \eta^{5}-\frac{1}{4} \eta^{4}+\frac{1}{6} \eta^{3}\right) \\
+\frac{9201899729}{600000000000} \operatorname{SPr} \eta
\end{gathered}
$$

The terms $f_{i}(\eta), \Theta_{i}(\eta)$ when $i>2$ are too large that is mentioned graphically. The solution of this equation, when $p \rightarrow 1$, will be as follows :

$$
\begin{gathered}
f(\mathrm{\eta})=f_{0}(\mathrm{\eta})+f_{1}(\mathrm{\eta})+f_{2}(\mathrm{\eta})+f_{3}(\mathrm{\eta})+\cdots \\
=\sum_{i=0}^{N} f_{i}(\mathrm{\eta}) \\
\theta(\mathrm{\eta})=\theta_{0}(\mathrm{\eta})+\theta_{1}(\mathrm{\eta})+\theta_{2}(\mathrm{\eta})+\theta_{3}(\mathrm{\eta})+\cdots \\
=\sum_{i=0}^{N} \theta_{i}(\mathrm{\eta})
\end{gathered}
$$

\section{Results and discussion}

In this work, the unsteady squeezing nanofluid flow and heat transfer between two parallel plates in the attendance of viscous dissipations impact, and considering the Fourier heat flux model of heat conduction are studied Semianalytically by using method The Homotopy Perturbation Method (HPM). To verify the present analytical solution, we compared our results with results given by using 
Table 1 : Comparison the Present results with two different methods (HPM) and (RK).

\begin{tabular}{|c|c|c|c|c|}
\hline \multirow{3}{*}{$\mathrm{S}$} & \multicolumn{4}{|c|}{$\begin{array}{c}\text { Present results }(\varphi=0.02, E c=0.01, \operatorname{Pr}=6.2 \text {, } \\
\delta=0.1)\end{array}$} \\
\hline & \multicolumn{2}{|c|}{$\begin{array}{l}\text { The Rung-Kutta Method } \\
\text { (RK) }\end{array}$} & \multicolumn{2}{|c|}{$\begin{array}{l}\text { The Homotopy Perturbation Method } \\
\text { (HPM) }\end{array}$} \\
\hline & $-f^{\prime \prime}(1)$ & $-\theta^{\prime}(1)$ & $-f^{\prime \prime}(1)$ & $-\theta^{\prime}(1)$ \\
\hline-1.0 & 591711670 & 517392479 & 5.591715131 & 1.517339344 \\
\hline-0.5 & 5.799635516 & 1.453320934 & 5.799635615 & 1.453317763 \\
\hline-0.1 & 5.960500492 & 1.405664454 & 5.960500487 & 1.405664446 \\
\hline 0.0 & 6.0000000 & 94 & 6.00000000 & 1.394213021 \\
\hline 0.01 & 003934651 & 1.393077678 & 6.003934637 & 1.393077674 \\
\hline 0.1 & 6.039222572 & 1.382938524 & 6.039222564 & 1.382938511 \\
\hline 0.2 & 6.078172838 & 1.371837113 & 6.078172818 & 1.371837028 \\
\hline 0.3 & 6.116855340 & 1.360905070 & 6.116855315 & 1.360904683 \\
\hline 0.5 & 6.193434683 & 1.339534832 & 6.193434559 & 1.339531970 \\
\hline 1.0 & 6.380494566 & 1.288834807 & 6.380491471 & 1.28879168 \\
\hline 1.5 & 6.561671376 & 1.241727015 & 6.561648736 & 1.24151864 \\
\hline
\end{tabular}
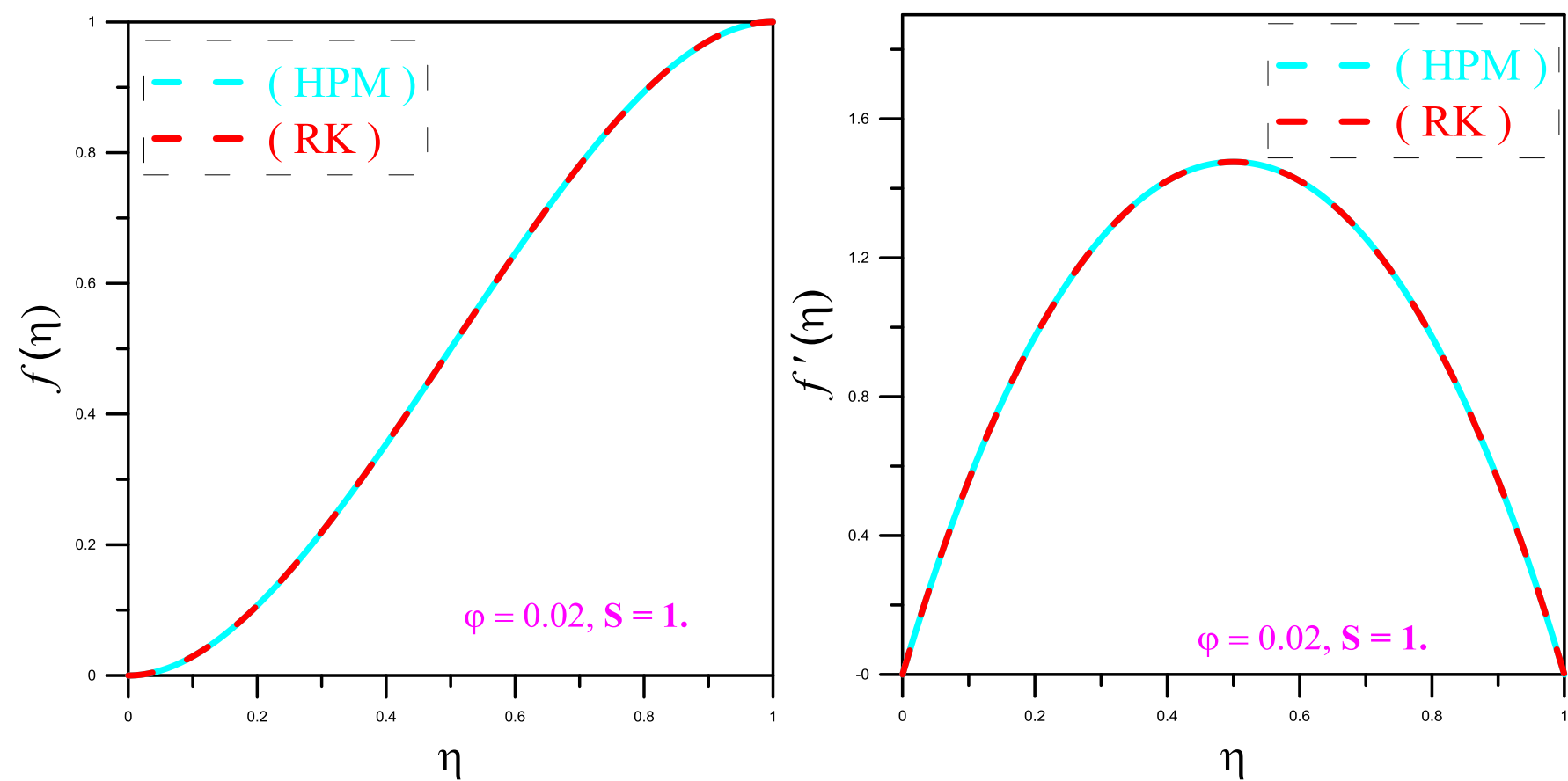

Figure 2 : comparison between the results given by ( HPM ) and ( RK ) for $f(\eta)$ and $f^{\circ}(\eta)$.

Runge-Kutta. They are in an excellent agreement as they have been demonstrated in Table $\mathbf{1}$ and Figure 2 - Figure 3.

To describe the physical insight of the present problem in depth, the thermodynamic flow behaviour of skin friction coefficient and Nusselt numbers along with velocity and temperature profiles in the flow region for different set physical parameters namely, squeezing parameter $S$, Eckert number $E c$, Prandtl number $\mathrm{Pr}$, are investigated. For better understanding of the numerical results, the computer generated numerical data are presented in the form of graphs and tables. The graphs are drawn for the copper 
nanoparticles and water (Cu-Water). The thermophysical properties of nanofluid have been epitomized in Table 2.
Figure 4 - Figure 5 shows the effect of increasing the squeeze number $S$ on the profile of the axial and radial velocity the latter increasing to the movable

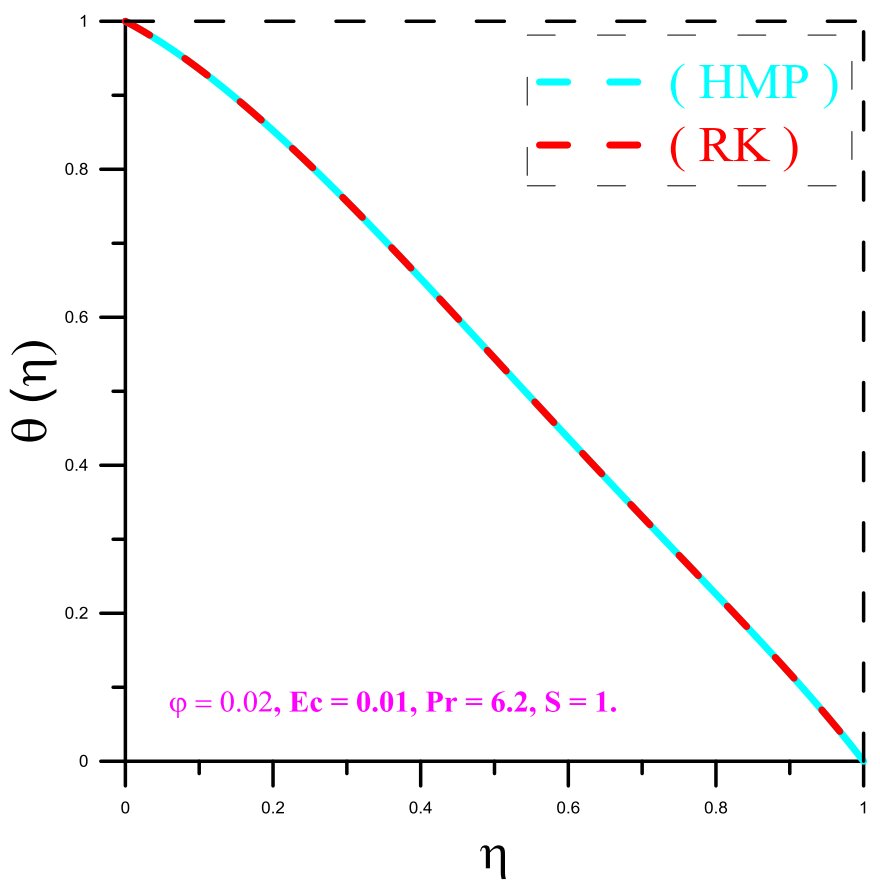

Figure 3 : comparison between the results given by ( HPM ) and ( RK ) for $\theta(\eta)$.

Table 2: Thermophysical properties of pure water and nanoparticles.

\begin{tabular}{|c|c|c|c|c|}
\hline & $\rho\left(\mathrm{Kg} / \mathrm{m}^{3}\right)$ & $\mathrm{Cp}(\mathrm{J} / \mathrm{Kg})$ & $\mathrm{K}(\mathrm{W} / \mathrm{mK})$ & $\sigma\left(\mathrm{S} \mathrm{m}^{-1}\right)$ \\
\hline Copper $(\mathrm{Cu})$ & 8933 & 385 & 401 & $5.96 * 10^{7}$ \\
Pure water $\left(\mathrm{H}_{2} \mathrm{O}\right)$ & 997.1 & 4179 & 0.613 & 0.05 \\
Alumina $\left(\mathrm{Al}_{2} \mathrm{O}_{3}\right)$ & 3970 & 765.0 & 40.000 & $1 * 10^{-10}$ \\
Silver $(\mathrm{Ag})$ & 10.500 & 235 & 429 & $6.3 * 10^{7}$ \\
Gold $(\mathrm{Au})$ & 19.300 & 129 & 318 & $4.52 * 10^{7}$ \\
\hline
\end{tabular}

plate is in the middle of the initial distance between the plates, then it decreases slightly and tends towards zero when the two plates are glued together, and we also observe that the speed decreases with increasing values of S.

Figure 6 portrays the impact of the volume fraction $\varphi$ on the velocity profile, Considering the curve of Figure 6 we observe practically no change in the velocity profile when $\varphi$ varies, but there is an effect well shown in the following Table 3, according to Table 3 we observe that the

velocity rise when phi increases in the
region $0<\eta<0.5$, and decreases in the region $0.5<\eta<1$.

The influence of Eckert number $E c$ on temperature profile is illustrated in the Figure 7. It is observed from Figure 7 that, the temperature profile enhanced for the increasing values of Eckert number. However, this upsurge in temperature profile is expected because $E c$ has direct impact on the heat dissipation process and hence increases the temperature field in the flow region. 
Similarly, the impact of Prandtl number $\operatorname{Pr}$ on temperature profiles is depicted in the Figure 8. However, it is remarked from the Figure 8 that, the temperature profile enhanced for the increasing values of Prandtl number in the flow region. This variation in temperature profile is mainly due to the fact that, the larger Values of $P r$

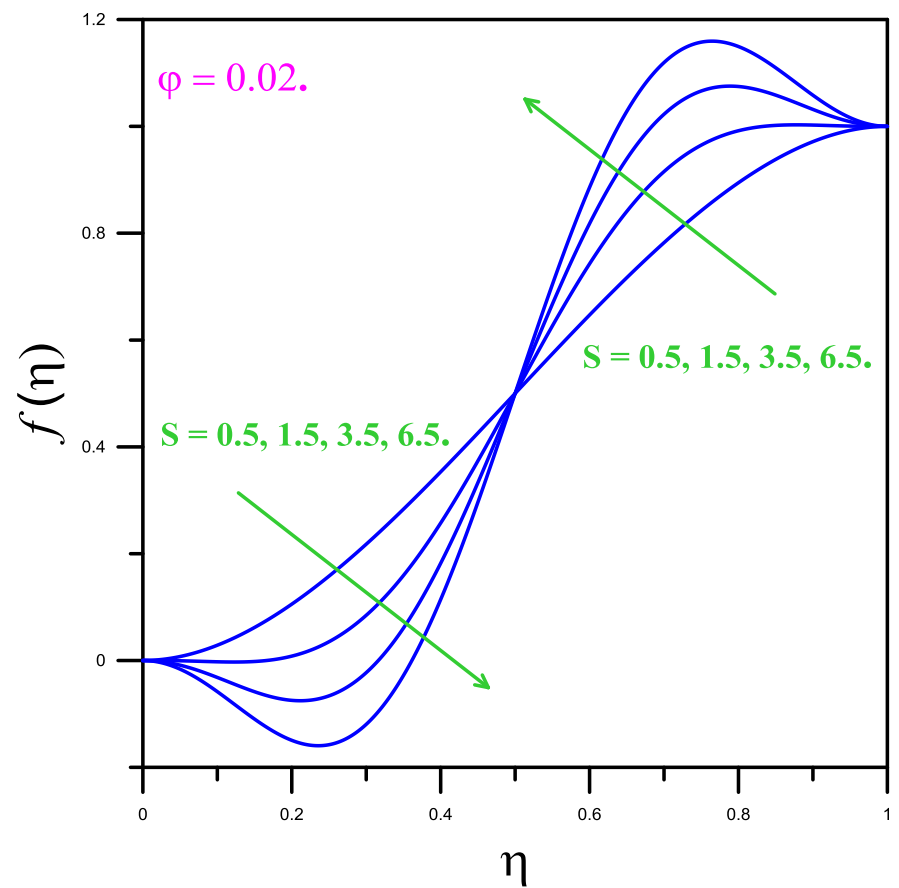

Figure 4 : Impact of $S$ on $f(\eta)$.

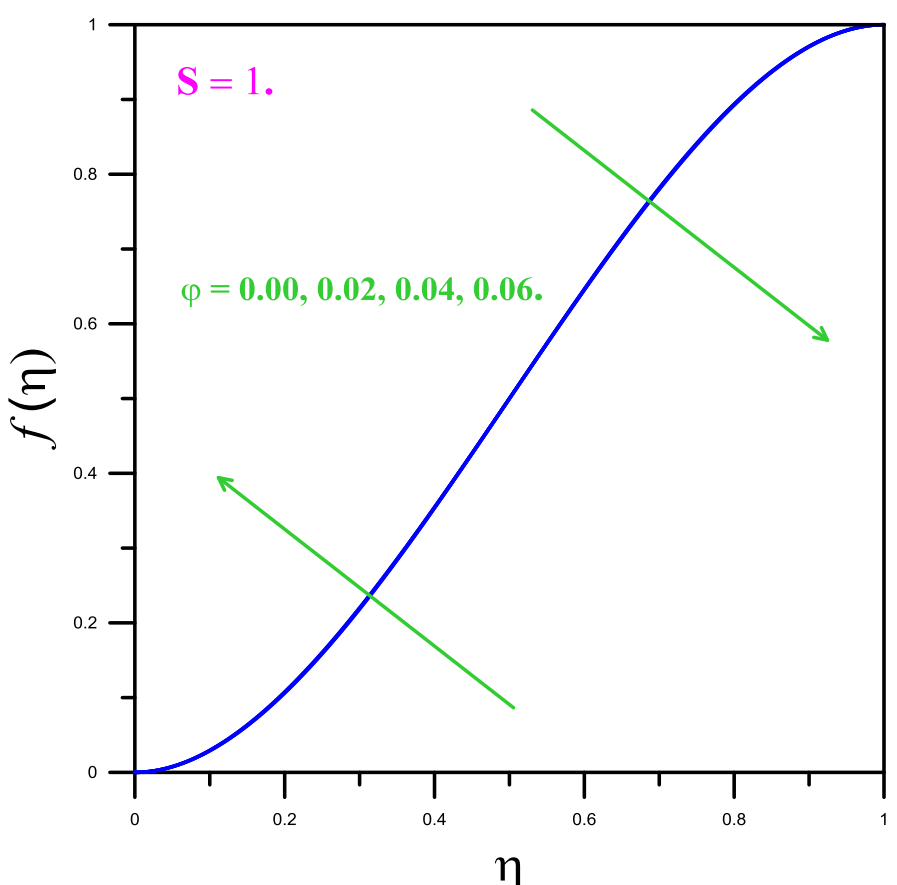

Figure 6 : Impact of $\varphi$ on $f(\eta)$. considerably reduces the thermal diffusivity and decreases the thickness of the thermal boundary layer and which in turn responsible for the increment of thermal profile in the flow regime.

Figure 9 we observe practically change in the velocity profile when the squeese number $\mathrm{S}$ varies,

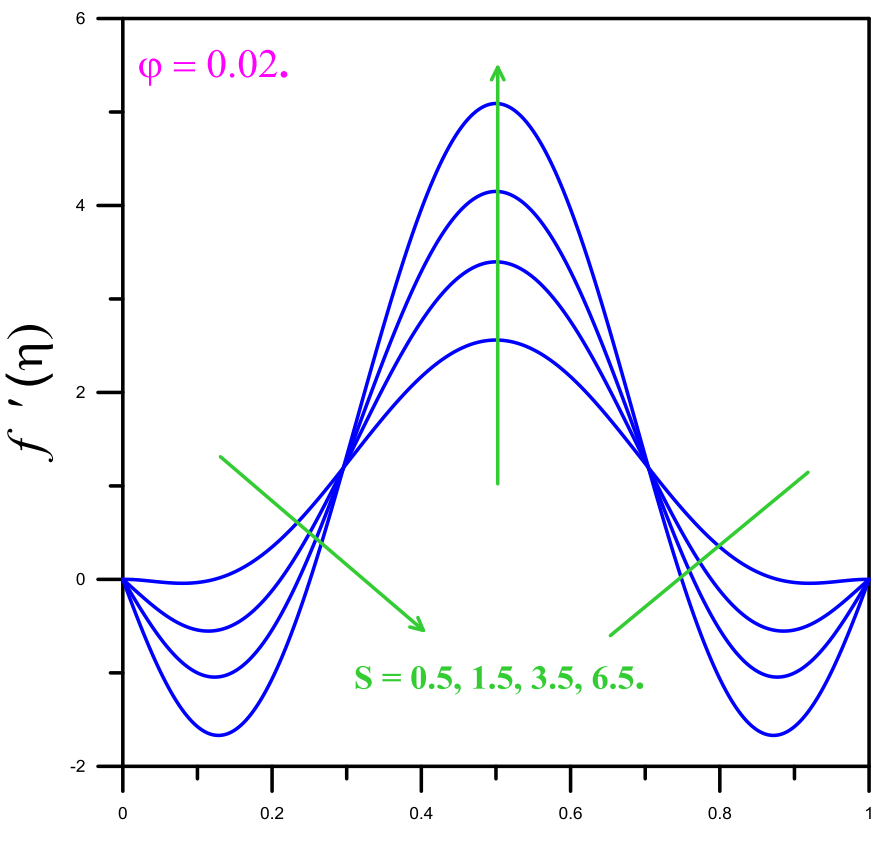

$\eta$

Figure 5 : Impact of $S$ on $f(\eta)$.

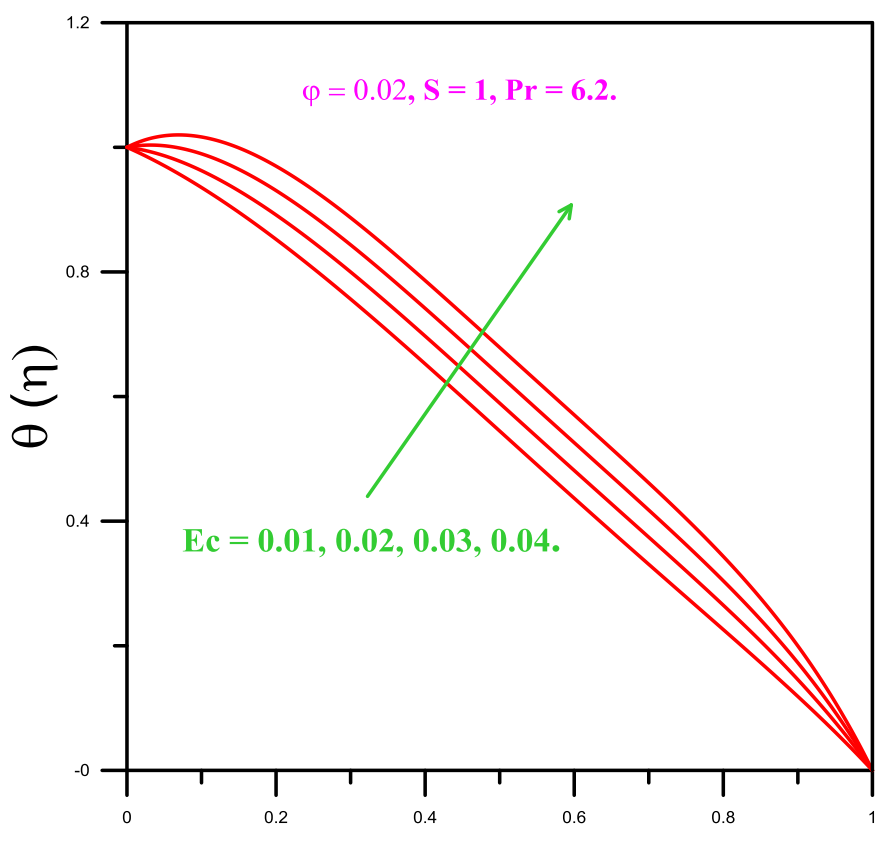

$\eta$

Figure 7 : Impact of $E c$ on $\theta(\eta)$. 
Table 3 : Velocity value for different values of $\varphi$.

\begin{tabular}{|c|c|c|c|c|c|c|}
\hline \multirow{2}{*}{$\eta$} & \multicolumn{7}{|c|}{$S=1}$. \\
\cline { 2 - 7 } & $\varphi=0.01$ & $\varphi=0.02$ & $\varphi=0.03$ & $\varphi=0.04$ & $\varphi=0.05$ & $\varphi=0.06$ \\
\cline { 2 - 8 } & $f$ & $f$ & $f$ & $f$ & $f$ & $f$ \\
\hline 0 & 1 & 1 & 1 & 1 & 1 & 1 \\
\hline 0.1 & 0.0291871774 & 0.0292404961 & 0.0292899321 & 0.0293356158 & 0.0293776727 & 0.0294162238 \\
\hline 0.2 & 0.1068277623 & 0.1069539313 & 0.1070708472 & 0.1071788328 & 0.10727819797 & 0.1073692399 \\
\hline 0.3 & 0.2192583687 & 0.2194030567 & 0.2195370789 & 0.2196608175 & 0.2197746383 & 0.2198788914 \\
\hline 0.4 & 0.3541320709 & 0.3542264711 & 0.3543138908 & 0.3543945841 & 0.3544687942 & 0.3545367528 \\
\hline 0.5 & 0.4999999998 & 0.4999999999 & 0.5000000000 & 0.4999999998 & 0.5000000000 & 0.4999999999 \\
\hline 0.6 & 0.6458679288 & 0.6457735288 & 0.6456861091 & 0.6456054155 & 0.6455312058 & 0.6454632470 \\
\hline 0.7 & 0.7807416309 & 0.7805969431 & 0.7804629210 & 0.7803391821 & 0.7802253617 & 0.7801211084 \\
\hline 0.8 & 0.8931722373 & 0.8930460684 & 0.8929291527 & 0.8928211667 & 0.8927218021 & 0.8926307598 \\
\hline 0.9 & 0.9708128220 & 0.9707595035 & 0.9707100677 & 0.9706643836 & 0.9706223274 & 0.9705837758 \\
\hline 1 & 0 & 0 & 0 & 0 & 0 & 0 \\
\hline
\end{tabular}

according to Figure 9 we observe that the temperature decreases when phi increases in the region $0<\eta<0.5$, and rise in the region $0.5<\eta<1$.

The effect of the volume fraction $\varphi$ on the temperature is well shown in Figure 10, from the Figure $\mathbf{1 0}$ it is obvious that the temperature profile increased when the $\varphi$ value increases because the rise in the volume fraction value increases the friction between the particles nanofluid so increase the temperature.

From Table 4 it is evident that the coefficient of friction and the Nusselt number are proportional to $S$, and it is observed that the parameters $C_{f}^{*}$ increase with increasing values of $S$ and $N_{u}^{*}$ decrease as $\mathrm{S}$ increases.

In Table $\mathbf{5}$ it is evident that the coefficient of friction and the Nusselt number are inversely proportional to $\varphi, C_{f}^{*}$ and $N_{u}^{*}$ decreases as $\varphi$ increases.

The comparison for metallic nanoparticles (Ag, $\mathrm{Cu}$, and $\mathrm{Au})$ and nonmetallic nanoparticles $\left(\mathrm{Al}_{2}\right.$ $\left.\mathrm{O}_{3}\right)$ is done in Table 6.

Table 4: Variation of $C_{f}^{*}$ and $N_{u}^{*}$ for different values of $\mathrm{S}$.

\begin{tabular}{|c|c|c|}
\hline \multirow{2}{*}{$S$} & \multicolumn{2}{|c|}{$\operatorname{Pr}=6.2, \varphi=0.02, E c=$} \\
\cline { 2 - 3 } & $C_{f}^{*}$ & $N_{u}^{*}$ \\
\hline 0.5 & 5.61973 & 0.88071 \\
\hline 1 & 5.78950 & 0.84032 \\
\hline 1.5 & 5.95406 & 0.80209 \\
\hline 2 & 6.11394 & 0.76587 \\
\hline
\end{tabular}

Table 5 : Variation of $C_{f}^{*}$ and $N_{u}^{*}$ for different values of $\varphi$. 
Table 6 : Variation of $C_{f}^{*}$ and $N_{u}^{*}$ for different nanoparticles.

\begin{tabular}{|c|c|c|}
\hline Nanoparticles & $c_{f}$ & $N_{u}$ \\
\hline Gold $(\mathrm{Au})$ & 6.323437982 & 1.29475305 \\
\hline Copper $(\mathrm{Cu})$ & 6.380491471 & 1.28744224 \\
\hline Silver $(\mathrm{Ag})$ & 6.323381375 & 1.29476136 \\
\hline $\begin{array}{c}\text { Alumina }\left(\mathrm{Al}_{2}\right. \\
\left.\mathrm{O}_{3}\right)\end{array}$ & 6.348795072 & 1.28770311 \\
\hline
\end{tabular}

\section{Conclusions}

The present paper deals with the numerical solution of heat transfer effect of an unsteady two dimensional flow of incompressible viscous nanofluids in middle of two parallel plates extended infinitely in the attendance of viscous dissipations impacts, The relevant nonlinear partial differential equations were transformed to a set of ordinary differential equations and then are solved analytically using the homotopy perturbation method (HPM), From the above discussion the eye-catching results are as follows.

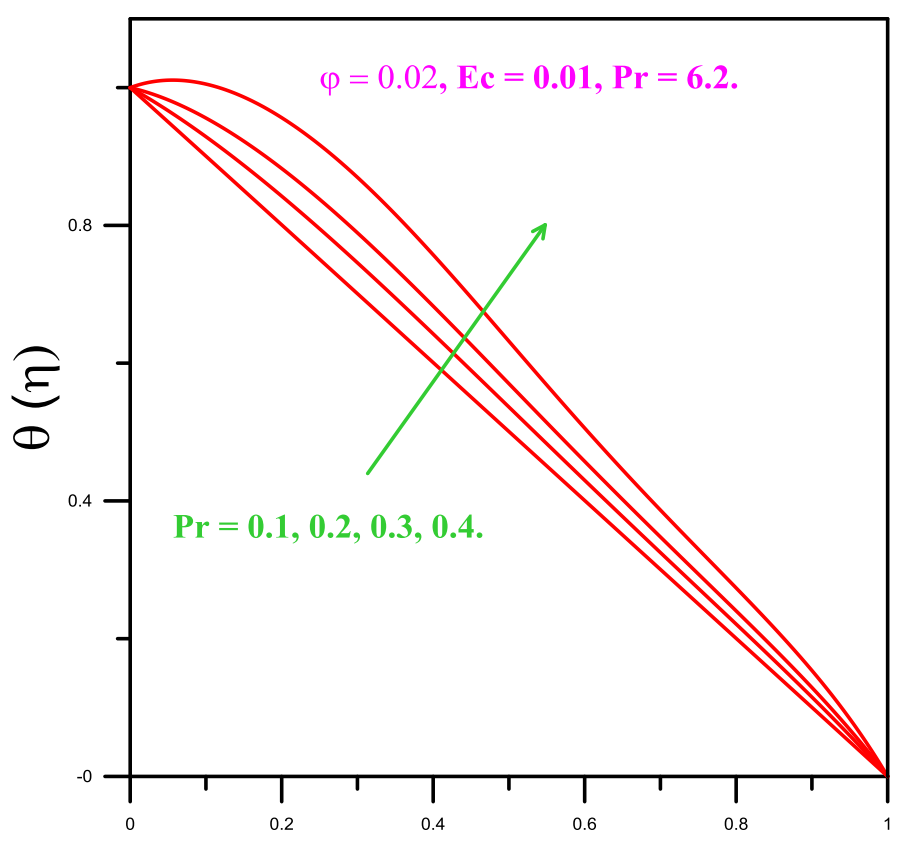

$\eta$

Figure 8: Impact of $\operatorname{Pr}$ on $\theta(\eta)$.

\begin{tabular}{|c|c|c|}
\hline \multirow{2}{*}{$\varphi$} & \multicolumn{2}{|c|}{$\operatorname{Pr}=6.2, S=1, E c=0.01$} \\
\cline { 2 - 3 } & $C_{f}^{*}$ & $N_{u}^{*}$ \\
\hline 0 & 6.34632 & 0.90222 \\
\hline 0.01 & 6.04486 & 0.87082 \\
\hline 0.02 & 5.78950 & 0.84032 \\
\hline 0.03 & 5.57157 & 0.81069 \\
\hline 0.04 & 5.38450 & 0.78190 \\
\hline 0.05 & 5.22323 & 0.75391 \\
\hline
\end{tabular}

- The temperature increases in $\mathrm{Cu}$-water nanofluid with an increase in the volume fraction $\varphi$.

- The temperature increases in $\mathrm{Cu}$-water nanofluid with an increase in the Eckert number $E c$.

- The temperature increases in $\mathrm{Cu}$-water nanofluid with an increase in the Prandtl number $\mathrm{Pr}$.

- The coefficient of friction and the Nusselt number are proportional to squeese number $S$.

- The coefficient of friction and the Nusselt number are inversely proportional to the volume fraction $\varphi$.

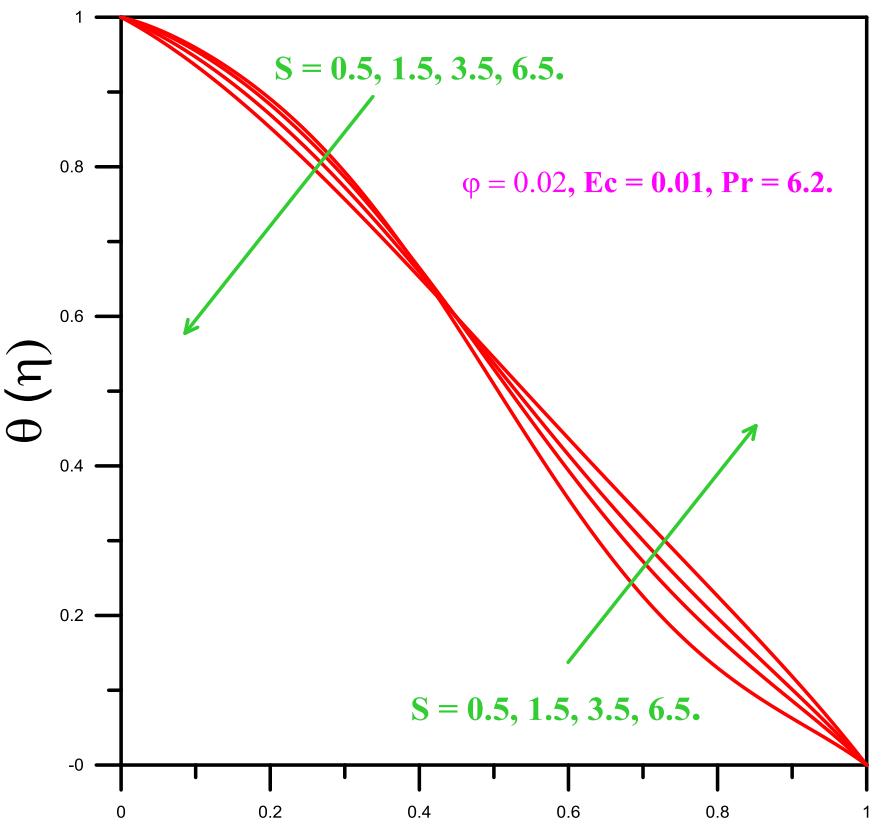

$\eta$

Figure 9 : Impact of $S$ on $\theta(\eta)$. 


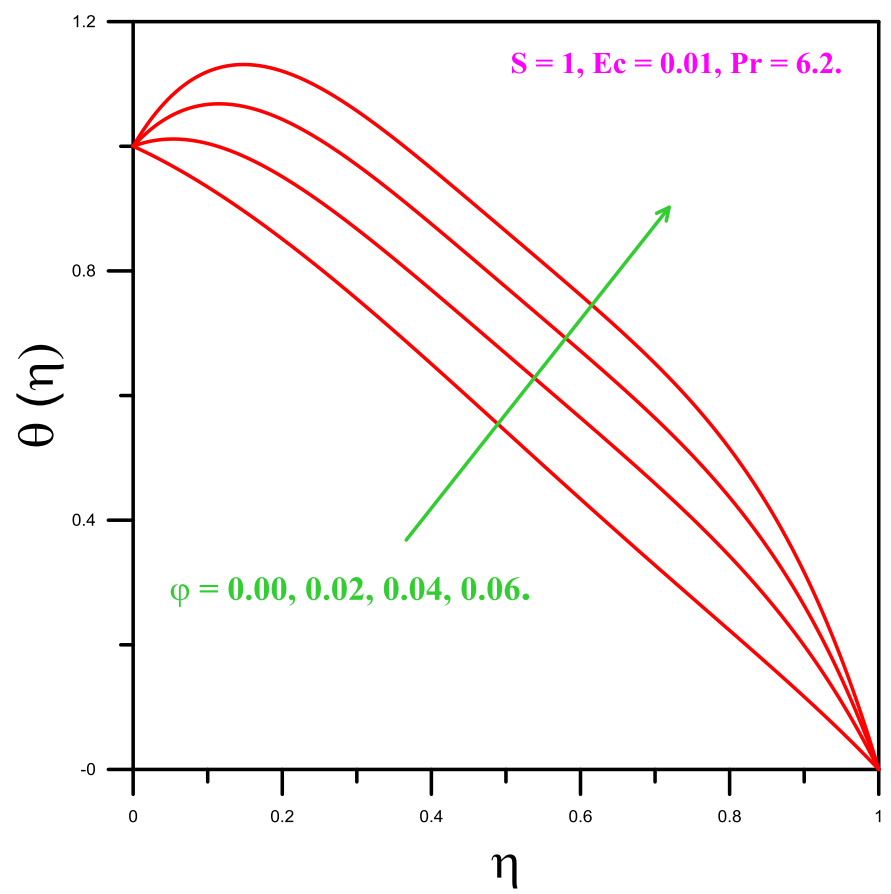

Figure 10 : Impact of $\varphi$ on $\theta(\eta)$.

\section{References}

[1] S. U. S. Choi and J. A. Eastman, "Enhancing thermal conductivity of fluids with nanoparticle," in Proceedings of the International Mechanical Engineering Congress and Exhibition, vol. 231, pp. 99-105, San Francisco, Calif, USA, November 1995.

[2] M. J. Stefan, "Versuch"uber die scheinbare adhesion sitzungsbers "achs," Akademie der Wissenschaften in Wien. Mathematisch- Naturwissenschaftliche Klasse, vol. 69, pp. 713-721, 1874.

[3] G. Domairry and M. Hatami, "Squeezing $\mathrm{Cu}-$ water nanofluid flow analysis between parallel plates by DTM-Pad'e Method," Journal of Molecular Liquids, vol. 193, pp. 37 44, 2014.

[4] U. Khan, N. Ahmed, M. Asadullah, and S. T. Mohyud-din, "Effects of viscous dissipation and slip velocity on two- dimensional and axisymmetric squeezing flow of $\mathrm{Cu}$-water and Cukerosene nanofluids," Propulsion and Power Research, vol. 4, no. 1, pp. 40-49, 2015.

[5] M. Sheikholeslami, D.D. Ganji, Heat transfer of $\mathrm{Cu}$-water nanofluid flow between parallel plates, Powder Technology 235 (2013) 873-879.

[6] J.H. He, Comparison of homotopy perturbation method and homotopy analysis method, Appl. Math. Comput., 156, (2004), 527-539.

[7] S.M. Moghimi, D.D. Ganji, H. Bararnia ,M. Hosseini, M. Jalaal, Homotopy perturbation method for nonlinear MHD JefferyHamel problem. Computers and Mathematics with Applications, 61, (2011)22132216.

[8] M. Mustafa, T. Hayat, S. Obaidat, On heat and mass transfer in the unsteady squeezing flow between parallel plates, 
Meccanica, DOI 10.1007/s11012-0129536-3.

[9] A. M. Siddiqui, M. Ahmed and Q. K. Ghori. Couette and Poiseuille flow for non- Newtonian fluids. International Journal of Nonlinear Sciences and (Attribution 4.0 International, CC BY 4.0)

This article is published under the terms of the Creative Commons Attribution License 4.0 Numerical Simulation, 7(1):15-26, 2006. [10] J.H. He. New interpretation of homotopy perturbation method. International Journal of Modern Physics B, 20(18):25612568, 2006.

[11] J.H. He. Some asymptotic methods for strongly nonlinear equations. International Journal of Modern Physics B, 20(10):1141-1199, 2006.

[12] A. El Harfouf, A. Wakif, S.Hayani Mounir, Heat Transfer analysis on Squeezing Unsteady MHD Nanofluid Flow between Two Parallel Plates Considering Thermal Radiation, Magnetic and Viscous Dissipations Effects a solution by using Homotopy Perturbation Method, SENSOR LETTERS, Vol. 17, 1-9, 2019, doi : 10.1166/s1.2020.4169. 